\title{
Host Range Specificity in Verticillium dahliae
}

\author{
R. G. Bhat and K. V. Subbarao
}

Department of Plant Pathology, University of California, Davis, c/o U.S. Agricultural Research Station, Salinas, CA 93905. Accepted for publication 7 September 1999.

\begin{abstract}
Bhat, R. G., and Subbarao, K. V. 1999. Host range specificity in Verticillium dahliae. Phytopathology 89:1218-1225.

Verticillium dahliae isolates from artichoke, bell pepper, cabbage, cauliflower, chili pepper, cotton, eggplant, lettuce, mint, potato, strawberry, tomato, and watermelon and V. albo-atrum from alfalfa were evaluated for their pathogenicity on all 14 hosts. One-month-old seedlings were inoculated with a spore suspension of about $10^{7}$ conidia per ml using a root-dip technique and incubated in the greenhouse. Disease incidence and severity, plant height, and root and shoot dry weights were recorded 6 weeks after inoculation. Bell pepper, cabbage, cauliflower, cotton, eggplant, and mint isolates exhibited host specificity and differential pathogenicity on other hosts, whereas isolates from artichoke, lettuce, potato, strawberry, tomato, and watermelon did not. Bell pepper was resistant to all Verticillium isolates except isolates from bell pepper and eggplant. Thus,

complementation of nitrate nonutilizing (nit) mutants. Cabbage and cauliflower isolates did not produce nit mutants. The isolate from cotton belonged to VCG 1; isolates from bell pepper, eggplant, potato, and tomato, to VCG 4; and the remaining isolates, to VCG 2. These isolates were also analyzed using the random amplified polymorphic DNA (RAPD) method. Forty random primers were screened, and eighteen of them amplified DNA from Verticillium. Based on RAPD banding patterns, cabbage and cauliflower isolates formed a unique group, distinct from other $V$. dahliae and V. albo-atrum groups. Minor genetic variations were observed among $V$. dahliae isolates from other hosts, regardless of whether they were host specific or not. There was no correlation among pathogenicity, VCGs, and RAPD banding patterns. Even though the isolates belonged to different VCGs, they shared similar RAPD profiles. These results suggest that management of Verticillium wilt in some crops through crop rotation is a distinct possibility.
\end{abstract} host specificity exists in some isolates of $V$. dahliae. The same isolates were characterized for vegetative compatibility groups (VCGs) through

Two Verticillium species, V. dahliae Kleb. and V. albo-atrum Reinke \& Berthier, are of major economic importance because of the vascular wilt diseases they cause on a broad range of host plants (27). These soilborne plant pathogens are distributed throughout the world (34). In North America, V. dahliae causes wilt on economically important crops such as vegetables, fiber, fruit and nut trees, legumes, forest trees, and woody and herbaceous ornamentals $(12,23,25,45,49)$. The pathogen is widely distributed in the agricultural soils in California, affecting such diverse crops as artichoke, cotton, pepper, pistachio, potato, strawberry, tomato, watermelon, and a number of crucifer crops.

New Verticillium wilt diseases are emerging in vegetable crops once considered as nonhosts. A sudden appearance of Verticillium wilt on lettuce in California in 1995 was both puzzling and a serious threat to the lettuce industry in California (45). Since 1990, commercial cauliflower in coastal California has been severely affected by Verticillium wilt caused by $V$. dahliae (23). This pathogen was also associated with symptoms of root discoloration in horseradish of commercial production fields in Illinois (13). Few other plant-pathogenic fungi exhibit the extraordinary plasticity of $V$. dahliae and its ability to infect a multitude of economically important crops.

Verticillium species vary in pathogenicity on different hosts. Isolates from a given host cause a range of symptoms in other hosts, but generally, symptoms are most severe on the host from which they were obtained. In some isolates of Verticillium, host specialization is more pronounced. For example, $V$. dahliae from peppermint, cocoa, pepper, and tobacco $(8,17,18,39,46,47)$ and $V$. albo-atrum from alfalfa and hops have limited host ranges $(10,19)$. Previous studies, however, have determined the pathogenicity of a number

Corresponding author: K. V. Subbarao; E-mail address: kvsubbarao@ucdavis.edu

Publication no. P-1999-1022-01R

(C) 1999 The American Phytopathological Society
Additional keywords: neutral molecular markers, vegetable crops.

of $V$. dahliae and $V$. albo-atrum isolates either on a single host plus their host of origin or have tested the cross-pathogenicity of one or two isolates from specific crops on a set of host plants. An overwhelming majority of previous host range studies on $V$. dahliae have been limited to isolates from a few hosts $(6,9,15,18,25$, 41,49).

An understanding of the genetic variation among $V$. dahliae strains from different hosts would contribute to the improvement of management schemes for this important disease. Vegetative compatibility in fungi is the ability of hyphae from two strains of a species to anastomose and form a stable heterokaryon. Gene flow and genetic recombinations occur through vegetative compatibility in fungi such as Verticillium, which have no documented sexual cycle (16). Heterokaryon or vegetative incompatibility results in separate but distinct gene pools in a fungal species, which may differ in many characteristics. These distinct populations, termed vegetative compatibility groups (VCGs), are stable (40).

Since hyphal contacts and heterokaryon formation between two strains are not easily observed, induced auxotrophic and color mutants were used earlier to study compatibility and to obtain heterokaryons with prototrophic traits $(32,35,37)$. Since then, nitrate nonutilizing (nit) mutants have been used for this purpose in $V$. dahliae $(1,7,11$, $14,20,30,42)$ and in $V$. albo-atrum (10). Unlike auxotrophic color mutants, nit mutants can be generated without employing mutagens. Based on these studies involving complementation analyses, $V$. dahliae have been grouped into four or five VCGs and V. albo-atrum into two or three VCGs. However, VCGs of recently described strains of $V$. dahliae in California from lettuce and peppers are not known.

In recent years, a number of molecular genetic techniques have been employed to understand relationships among Verticillium species and subspecific groups and in elucidating genetic diversity within Verticillium (40). Internal transcribed spacer regions of the ribosomal genes (rDNA or rRNA) have been used to detect and differentiate Verticillium species. $(29,31,43)$. Polymorphisms in the intergenic spacer region of the nuclear rDNA allowed Subbarao et 
al. (43) to show that $V$. dahliae isolates from cauliflower were different from isolates from other hosts. Others $(5,33)$ have used restriction fragment length polymorphisms (RFLPs) to study variations in several isolates of Verticillium. Recently, polymerase chain reaction (PCR)-mediated random amplified polymorphic DNA (RAPD) technique has allowed the characterization of $V$. dahliae $(28,38)$ and $V$. albo-atrum $(2,22)$. However, $V$. dahliae isolates of crops such as cauliflower, lettuce, and peppers from California have not been extensively characterized at the molecular level. If unique neutral molecular markers for these isolates are available, they could be used for isolate identification, comparison, and field monitoring of the spread of the pathogen.

To recommend suitable crop rotations, especially in areas such as the central coast of California that produce a bewildering array of crops, determination of the host range specificity and virulence spectrum of Verticillium strains present in the different cropping systems is important. Also, it is useful to know the genetic relatedness among isolates by determining the vegetative compatibility and DNA polymorphism, so that gene flow in the population could be ascertained. Therefore, the objectives of this study were to (i) evaluate host range specificity in $V$. dahliae isolates from various hosts, (ii) determine vegetative compatibility in $V$. dahliae isolates by complementing nit mutants, and (iii) analyze genetic variation in $V$. dahliae populations using RAPD. Preliminary results have been published $(3,4)$.

\section{MATERIALS AND METHODS}

Isolates and host plants. Isolates of $V$. dahliae from various hosts and $V$. albo-atrum from alfalfa were used in the host range analyses (Table 1). These isolates were collected from diverse geographic locations in California and other parts of the United States. The identities of all single-spore isolates were confirmed on the basis of colony morphology, conidiophore formation, conidial production, and presence of microsclerotia. All isolates were designated with letters based on the Verticillium species and the binomial nomenclature of hosts from which they were originally isolated followed by serial numbers in the order they were collected in our laboratory. For example, VdLs.7 is a $V$. dahliae isolate from Lactuca sativa and its stock number is 7. Isolates were maintained on potato dextrose agar (PDA) slants in a refrigerator at $4^{\circ} \mathrm{C}$. Cultivars of host plants used in pathogenicity tests were obtained from seed companies (Table 1).

Host range analyses. Virulence of thirteen $V$. dahliae and one $V$. albo-atrum isolate was determined on all hosts listed in Table 1, following the method described by Koike et al. (23). Seeds were sown into autoclaved riverbed sand in seedling trays with 200 cells.
Plants were maintained on benches in a greenhouse until inoculation. Inoculum was prepared by growing isolates on PDA plates at room temperature for 1 month. Spore suspensions were prepared by adding $15 \mathrm{ml}$ of sterile distilled water to each plate and scraping the cultures with a spatula. The conidial density of each isolate was adjusted to approximately $10^{7}$ conidia per ml. Four-week-old plants were removed from the seedling trays and $2 \mathrm{~cm}$ of root was trimmed just before inoculation, since trimmed or intact roots do not affect the plant reaction (23). Ten plants of each of the 14 hosts were inoculated per isolate by dipping the roots in a spore suspension for at least $5 \mathrm{~min}$ and planting them individually into autoclaved soil in 12-cm-diameter pots. Roots of 10 plants of each host were trimmed, dipped in sterile distilled water, and maintained as noninoculated controls. Plants were arranged in a randomized block design on greenhouse benches.

After 6 weeks of incubation, all plants were gently uprooted and washed free of soil. Vascular discoloration was rated visually by longitudinally cutting the crown and main root of each plant. A scale of 0 to 4 was adopted to assess disease severity and wilting, in which $0=$ no vascular discoloration, $1=1$ to $25 \%$ vascular area discolored, $2=26$ to $50 \%$ vascular area discolored, $3=51$ to $75 \%$ vascular area discolored, and $4=76$ to $100 \%$ vascular area discolored with or without foliar wilting. An isolate was considered aggressive on a particular host if it caused a disease severity of 4 . Vascular discoloration in the shoot portion also was noted in some of the diseased plants. Growth parameters such as plant height and dry weights of shoot and root were recorded for each plant.

Pathogenicity tests were conducted twice. Analysis of variance was conducted on each variable to determine the overall effects of isolate, host, and isolate $\times$ host interaction. Replications within experiments and repetition were considered as random effects in the analysis. Means were computed for each isolate $\times$ host combination, and comparisons of isolates within a host were made using least significant difference tests $(P \leq 0.05)$. Based on the host response, isolates were grouped as either pathogenic or nonpathogenic.

Generation and characterization of nit mutants. nit Mutants in Verticillium were generated using techniques described previously $(24,36)$. A minimal medium (MM) and $1.5 \%$ water agar (WA), each containing $2.5 \%$ potassium chlorate $\left(\mathrm{KClO}_{3}\right)$, were used to generate nit mutants. To obtain mutants, an agar plug from each 2-week-old culture growing on PDA was placed in the center of a petri dish containing either $\mathrm{MM}$ with $\mathrm{KClO}_{3}(\mathrm{MMC})$ or WA with $\mathrm{KClO}_{3}$. Subcultured plates were incubated for 15 to 20 days. Mutants that emerged as fast-growing sectors were transferred to MM containing nitrate as the sole carbon source, and those sectors that grew as thin expansive colonies with no aerial mycelium were considered nit mutants. All nit mutants grew as wild types on PDA.

TABLE 1. Verticillium isolates, their host of origin and vegetative compatibility group, and the cultivars evaluated to determine the host range pathogenicity of isolates

\begin{tabular}{|c|c|c|c|c|}
\hline Isolate $^{a}$ & Original isolate number & Host & Cultivars & $\begin{array}{c}\text { Vegetative } \\
\text { compatibility group }\end{array}$ \\
\hline VaMs.102 & VP-1 & Alfalfa (Medicago sativus L.) & Common variety & $?^{\mathrm{b}}$ \\
\hline VdCs.80 & $91-04$ & Artichoke (Cynara scolymus L.) & $5473 / 91 B L K$ & 2 \\
\hline VdCa.59 & $\mathrm{B}$ and $\mathrm{T} 2$ & Bell pepper (Capsicum anпиит L.) & Early Cal Wonder & 4 \\
\hline VdBoc.74 & $91-05$ & Cabbage (Brassica oleracea var. capitata L.) & Grenadier & $?^{\mathrm{c}}$ \\
\hline VdBob.70 & $90-02$ & Cauliflower (Brassica oleracea var. botrytis L.) & White Rock & $?^{\mathrm{c}}$ \\
\hline VdCa.31 & $91-03$ & Chili pepper (Capsicum annuиm L.) & Sonora & 2 \\
\hline VdGh.101 & MD-05 & Cotton (Gossypium hirsutum L.) & Acala SJ-2 & 1 \\
\hline VdSm.113 & V1 & Eggplant (Solanum melongena L.) & Early Long Purple & 4 \\
\hline VdLs.7 & VdL-7 & Lettuce (Lactuca sativa L.) & Salinas & 2 \\
\hline VdMp.89 & OC-96-3 & Mint (Mentha $\times$ piperita L.) & Mint Common & 2 \\
\hline VdSt.91 & O28vd & Potato (Solanum tuberosum L.) & Norkotah & 4 \\
\hline VdFca.21 & SB1442 & Strawberry (Fragaria $\times$ ananassa Duchesne) & Pajaro & 2 \\
\hline VdLe. 88 & Tomato & Tomato (Lycopersicon esculentum Mill.) & EP 7 & 4 \\
\hline VdCv.85 & Watermelon & Watermelon (Citrullus vulgaris Schrader) & Sugar Baby & 2 \\
\hline
\end{tabular}

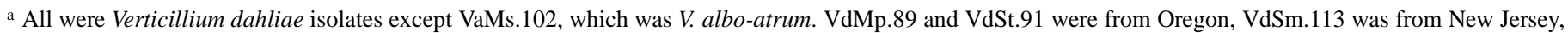

VaMs.102 was from Pennsylvania, and all other isolates were from California.

${ }^{\mathrm{b}}$ nit Mutants were incompatible with NitMs of $V$. dahliae, belonging to standard VCG 1, VCG 2, VCG 3, or VCG 4 .

c nit Mutants were not obtained. 
Complementation tests. Every nit mutant was paired with standard NitM tester strains of $V$. dahliae belonging to VCG 1 (strain T9), VCG 2 (strain 115), VCG 3 (strain PCW), and VCG 4 (strain S39) (42). A mycelial plug from each mutant was transferred to the center of a petri plate containing $\mathrm{MM}$, and the tester strains belonging to known VCGs were placed at equal distance (approximately $1 \mathrm{~cm}$ ) surrounding the unknown mutant isolate. Thus, a mutant had an equal chance to complement with any of the four VCGs. All plates were incubated at room temperature for about 4 weeks. When an unknown and a tester strain grew together, prototrophic growth with dense aerial mycelia, profuse sporulation, and microsclerotia formation was observed at the site of contact, where complementation occurred as a result of heterokaryon formation. In such cases, the unknown mutant was considered vegetatively compatible with the tester strain and was given the VCG number of the tester strain.

Comparison of isolates by RAPD analysis. A modification of the method described by Lee and Taylor (26) was followed to extract genomic DNA from Verticillium. Total genomic DNA was extracted from isolates used in host range analyses. DNA samples were stored at $-20^{\circ} \mathrm{C}$ until further use. A procedure described by Williams et al. (48) was followed for the RAPD assay, with certain modifications. Primers from Operon 10-mer kits (kits A and B; Operon Technologies, Inc., Alameda, CA) were screened. PCR was carried out in a total volume of $25 \mu \mathrm{l}$ of reaction mixture. The reaction mixture consisted of sterile distilled water, $1.5 \mathrm{mM} \mathrm{MgCl}$, $1 \times$ reaction buffer $(50 \mathrm{mM} \mathrm{KCl} ; 10 \mathrm{mM}$ Tris- $\mathrm{HCl}, \mathrm{pH} 9.0$; and $0.1 \%$ Triton X-100), $0.2 \mathrm{mM}$ dATP, $0.2 \mathrm{mM}$ dTTP, $0.2 \mathrm{mM}$ dGTP, $0.2 \mathrm{mM}$ dCTP, $0.2 \mu \mathrm{M}$ primer, 0.9 unit of Taq polymerase (Pro- mega Corp., Madison, WI), and 10 ng of DNA from Verticillium. One drop of mineral oil was overlaid on top of the reaction mixture in each tube. For amplification, the Peltier Thermal Cycler (PTC-200 DNA Engine; MJ Research, Inc., Watertown, MA) was programmed for 40 cycles of $30 \mathrm{~s}$ at $94^{\circ} \mathrm{C}, 1 \mathrm{~min}$ at $32^{\circ} \mathrm{C}$, and $2 \mathrm{~min}$ at $72^{\circ} \mathrm{C}$, with a final extension period of $10 \mathrm{~min}$ at $72^{\circ} \mathrm{C}$ and a ramp speed of $1^{\circ} \mathrm{C}$ per s. The amplified product was separated electrophoretically in $1.4 \%$ agarose gels (Sigma Chemical Co., St. Louis) and detected by staining with ethidium bromide and fluorescence UV illumination. Individual bands were scored as one of two discrete character states ( 0 and 1 for absence or presence, respectively, of RAPD bands). Molecular weight of bands was determined by comparison with standard 1-kilobase molecular weight markers. Phylogenetic relationships were calculated using PAUP version 4.0b2 (Sinauer Associates, Inc., Sunderland, MA).

\section{RESULTS}

Pathogenicity of $\boldsymbol{V}$. dahliae isolates on various crops. Analysis of variance of pathogenicity data indicated that all the variables were affected significantly $(P \leq 0.05)$ by the isolates, hosts, and isolate $\times$ host interactions. Replications within an experiment and interactions between isolate $\times$ experiment and host $\times$ experiment were not significant. Therefore, data from two experiments were combined and presented here. The $V$. dahliae isolate from chili pepper, VdCa.31, was nonpathogenic on all hosts evaluated. This isolate, however, was included in the analysis and genetic studies because it had all the characteristics of $V$. dahliae.

TABLE 2. Verticillium wilt incidence in various hosts inoculated with Verticillium isolates from various crops

\begin{tabular}{|c|c|c|c|c|c|c|c|c|c|c|c|c|c|c|c|}
\hline \multirow[b]{2}{*}{ Host } & \multicolumn{15}{|c|}{ Isolates } \\
\hline & VaMs.102 & VdCs.80 & VdCa.59 & VdBoc.74 & VdBob.70 & VdCa.31 & VdGh.101 & VdSm.113 & VdLs.7 & VdMp.89 & VdSt.91 & VdFca.21 & VdLe.88 & VdCv.85 & Control \\
\hline Alfalfa & $100^{\mathrm{a}}$ & 90 & 90 & 90 & 100 & 0 & 30 & 80 & 50 & 60 & 90 & 60 & 90 & 100 & 0 \\
\hline Artichoke & 100 & 100 & 100 & 100 & 80 & 30 & 70 & 100 & 100 & 80 & 100 & 100 & 100 & 100 & 0 \\
\hline Bell pepper & 30 & 20 & 100 & 0 & 20 & 10 & 30 & 100 & 10 & 60 & 80 & 0 & 60 & 60 & 0 \\
\hline Cabbage & 100 & 100 & 40 & 100 & 100 & 40 & 40 & 20 & 60 & 50 & 80 & 90 & 100 & 100 & 0 \\
\hline Cauliflower & 80 & 50 & 90 & 100 & 100 & 10 & 10 & 50 & 50 & 80 & 100 & 50 & 100 & 100 & 0 \\
\hline Chili pepper & 100 & 100 & 100 & 80 & 100 & 0 & 80 & 100 & 100 & 100 & 100 & 100 & 100 & 100 & 0 \\
\hline Cotton & 100 & 100 & 60 & 40 & 90 & 40 & 100 & 90 & 100 & 100 & 100 & 100 & 100 & 100 & 0 \\
\hline Eggplant & 90 & 100 & 100 & 50 & 60 & 0 & 60 & 100 & 100 & 100 & 100 & 100 & 100 & 100 & 0 \\
\hline Lettuce & 70 & 70 & 30 & 0 & 30 & 10 & 70 & 90 & 100 & 60 & 100 & 60 & 80 & 90 & 0 \\
\hline Mint & 0 & 100 & 20 & 20 & 30 & 10 & 0 & 20 & 100 & 100 & 100 & 100 & 50 & 100 & 0 \\
\hline Potato & 100 & 100 & 100 & 80 & 100 & 40 & 30 & 100 & 90 & 50 & 100 & 100 & 100 & 100 & 0 \\
\hline Strawberry & 100 & 90 & 100 & 100 & 100 & 10 & 50 & 100 & 60 & 100 & 100 & 100 & 100 & 90 & 0 \\
\hline Tomato & 70 & 100 & 90 & 0 & 10 & 0 & 20 & 40 & 70 & 10 & 50 & 100 & 100 & 100 & 0 \\
\hline Watermelon & 100 & 100 & 100 & 100 & 100 & 60 & 50 & 100 & 100 & 50 & 100 & 100 & 100 & 100 & 0 \\
\hline
\end{tabular}

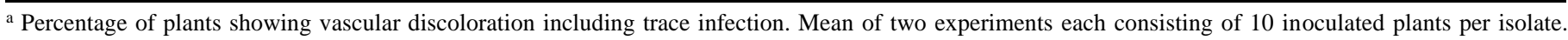
Equal number of inoculated plants served as a control.

TABLE 3. Verticillium wilt severity on plants inoculated with Verticillium isolates from various crops

\begin{tabular}{|c|c|c|c|c|c|c|c|c|c|c|c|c|c|c|c|}
\hline \multirow[b]{2}{*}{ Host } & \multicolumn{15}{|c|}{ Isolates } \\
\hline & VaMs.102 & VdCs.80 & VdCa.59 & VdBoc.74 & VdBob.70 & VdCa.31 & VdGh.101 & VdSm.113 & VdLs.7 & VdMp.89 & VdSt.91 & VdFca.21 & VdLe.88 & VdCv.85 & Control \\
\hline Alfalfa & $4^{\mathrm{a}}$ & 2 & 1 & 2 & 2 & 0 & 0 & 1 & 2 & 2 & 3 & 1 & 3 & 2 & 0 \\
\hline Artichoke & 4 & 4 & 3 & 3 & 2 & 0 & 1 & 4 & 4 & 3 & 4 & 4 & 4 & 4 & 0 \\
\hline Bell pepper & 0 & 0 & 4 & 0 & 0 & 0 & 0 & 2 & 0 & 1 & 1 & 0 & 1 & 1 & 0 \\
\hline Cabbage & 3 & 3 & 1 & 4 & 4 & 0 & 1 & 0 & 2 & 2 & 2 & 2 & 3 & 3 & 0 \\
\hline Cauliflower & 2 & 1 & 2 & 4 & 4 & 0 & 0 & 1 & 1 & 2 & 3 & 1 & 3 & 3 & 0 \\
\hline Chili pepper & 3 & 2 & 4 & 1 & 2 & 0 & 1 & 3 & 3 & 2 & 2 & 2 & 3 & 3 & 0 \\
\hline Cotton & 4 & 4 & 2 & 1 & 2 & 1 & 4 & 2 & 4 & 4 & 3 & 4 & 4 & 4 & 0 \\
\hline Eggplant & 3 & 3 & 3 & 1 & 1 & 0 & 1 & 4 & 4 & 2 & 4 & 4 & 4 & 4 & 0 \\
\hline Lettuce & 1 & 2 & 1 & 0 & 1 & 0 & 1 & 2 & 4 & 1 & 2 & 2 & 2 & 3 & 0 \\
\hline Mint & 0 & 3 & 0 & 0 & 0 & 0 & 0 & 0 & 3 & 4 & 3 & 3 & 2 & 3 & 0 \\
\hline Potato & 3 & 4 & 2 & 2 & 2 & 0 & 0 & 4 & 4 & 1 & 4 & 4 & 4 & 4 & 0 \\
\hline Strawberry & 4 & 3 & 3 & 3 & 3 & 0 & 1 & 4 & 3 & 3 & 4 & 4 & 3 & 3 & 0 \\
\hline Tomato & 2 & 3 & 2 & 0 & 0 & 0 & 0 & 0 & 2 & 0 & 1 & 3 & 3 & 3 & 0 \\
\hline Watermelon & 4 & 4 & 4 & 3 & 3 & 1 & 1 & 4 & 4 & 1 & 4 & 4 & 4 & 4 & 0 \\
\hline
\end{tabular}

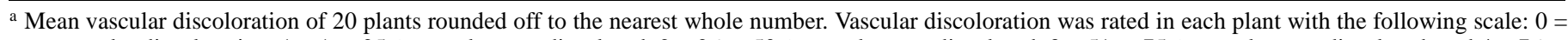
no vascular discoloration, $1=1$ to $25 \%$ vascular area discolored, $2=26$ to $50 \%$ vascular area discolored, $3=51$ to $75 \%$ vascular area discolored, and $4=76$ to $100 \%$ vascular area discolored with or without foliar wilting. Isolates that caused a disease severity of $\geq 2$ were considered pathogenic. 
Alfalfa. All $V$. dahliae isolates except the one from cotton caused root vascular discoloration in more than $50 \%$ of the alfalfa plants without causing any wilting (Tables 2 and 3). Among those that caused root discoloration, isolates from tomato and potato were more aggressive. Only the tomato isolate, however, significantly reduced plant height and root and shoot dry weights (Tables 4, 5, and 6). Isolates from bell pepper, cotton, eggplant, and strawberry were nonpathogenic. V. albo-atrum from alfalfa was highly pathogenic; it stunted and killed all alfalfa plants (Table 3). As a conse- quence, plant height and root and shoot dry weights were significantly reduced.

Artichoke. All isolates except the one from cotton caused root vascular discoloration in more than $70 \%$ of the artichoke plants (Table 2). Disease severity was greater in these plants (Table 3), and plant height and root and shoot dry weights were significantly different from the noninoculated control, except in plants inoculated with cauliflower and cabbage isolates (Tables 4, 5, and 6). The cotton isolate was nonpathogenic. The potato isolate was the

TABLE 4. Effect of Verticillium isolates from various crops on plant height of different hosts

\begin{tabular}{|c|c|c|c|c|c|c|c|c|c|c|c|c|c|c|c|c|}
\hline \multirow[b]{2}{*}{ Host } & \multicolumn{15}{|c|}{ Isolates } & \multirow[b]{2}{*}{$\mathrm{LSD}^{\mathrm{a}}$} \\
\hline & VaMs.102 & VdCs.80 & VdCa.59 & VdBoc.74 & VdBob.70 & $\mathrm{VdCa} .31$ & VdGh.101 & VdSm.113 & VdLs.7 & VdMp.89 & VdSt.91 & VdFca.21 & VdLe.88 & VdCv.85 & Control & \\
\hline Alfalfa & $17.7^{b}$ & 47.4 & 46.7 & 47.0 & 43.8 & 51.3 & 53.3 & 49.0 & 46.4 & 48.8 & 45.0 & 47.5 & 41.7 & 44.4 & 53.5 & 9.8 \\
\hline Artichoke & 18.7 & 17.7 & 16.8 & 22.3 & 21.4 & 21.9 & 24.6 & 12.3 & 16.1 & 19.0 & 11.8 & 15.3 & 13.5 & 14.5 & 22.8 & 3.5 \\
\hline Bell pepper & 26.4 & 27.7 & 12.6 & 26.5 & 26.3 & 27.1 & 27.1 & 24.3 & 26.3 & 28.4 & 27.3 & 27.3 & 26.9 & 27.1 & 27.6 & 2.1 \\
\hline Cabbage & 14.2 & 14.2 & 14.2 & 12.9 & 12.4 & 13.3 & 14.0 & 13.9 & 13.0 & 13.7 & 13.8 & 13.6 & 14.2 & 14.3 & 13.3 & 1.0 \\
\hline Cauliflower & 16.7 & 16.7 & 17.5 & 13.4 & 10.9 & 17.2 & 17.1 & 16.3 & 17.1 & 18.0 & 16.9 & 16.9 & 17.4 & 16.2 & 18.4 & 1.3 \\
\hline Chili pepper & 23.0 & 23.8 & 10.0 & 23.7 & 22.6 & 24.4 & 25.7 & 19.4 & 23.7 & 23.9 & 20.5 & 24.6 & 22.9 & 24 & 25.5 & 2.0 \\
\hline Cotton & 13.2 & 19.4 & 22.7 & 25.8 & 22.0 & 22.7 & 16.6 & 25.1 & 21.2 & 19.7 & 22.8 & 20.9 & 17.2 & 18.3 & 24.8 & 3.0 \\
\hline Eggplant & 30.4 & 32.0 & 29.1 & 38.3 & 36.1 & 38.9 & 36.8 & 24.0 & 22.3 & 34.4 & 19.2 & 27.9 & 26.0 & 25.8 & 38.8 & 3.0 \\
\hline Lettuce & 14.3 & 13.7 & 14.0 & 13.7 & 13.6 & 14.6 & 14.4 & 13.2 & 13.2 & 14.5 & 14.1 & 13.7 & 14.3 & 14.6 & 14.5 & 1.0 \\
\hline Mint & 31.9 & 24.1 & 26.6 & 25.9 & 29.1 & 27.7 & 25.8 & 24.4 & 25.1 & 21.1 & 26.5 & 24.2 & 25.1 & 25.2 & 29.9 & 5.3 \\
\hline Potato & 20.8 & 22.3 & 22.2 & 23.3 & 21.6 & 21.3 & 21.1 & 17.9 & 19.9 & 21.2 & 16.8 & 18.6 & 18.1 & 17.0 & 22.2 & 2.4 \\
\hline Strawberry & 18.5 & 18.7 & 19.4 & 21.6 & 18.3 & 19.4 & 22.6 & 18.6 & 18.1 & 18.6 & 18.3 & 19.4 & 18.4 & 20.1 & 20.2 & 3.3 \\
\hline Tomato & 45.1 & 46.4 & 45.5 & 48.1 & 45.9 & 49.5 & 45.9 & 44.9 & 45.9 & 46.7 & 44.5 & 45.0 & 46.5 & 47 & 47.6 & 2.4 \\
\hline Watermelon & 10.8 & 12.5 & 10.2 & 24.5 & 24.3 & 36.1 & 37.0 & 8.8 & 11.9 & 40.4 & 9.7 & 13.0 & 12.3 & 12.3 & 45.1 & 7.1 \\
\hline
\end{tabular}

${ }^{a}$ Least significant difference test at $P \leq 0.05$.

b Plant height in centimeters. Mean of two experiments each consisting of 10 inoculated plants per isolate. Equal number of inoculated plants served as a control.

TABLE 5. Effect of Verticillium isolates from various crops on root dry weight of different hosts

Isolates

\begin{tabular}{|c|c|c|c|c|c|c|c|c|c|c|c|c|c|c|c|c|}
\hline Host & VaMs. 102 & VdCs. 80 & VdCa.59 & VdBoc.74 & VdBob.70 & VdCa.31 & VdGh.101 & VdSm.113 & VdLs.7 & VdMp.89 & VdSt.91 & VdFca.21 & VdLe.88 & VdCv.85 & Control & $\mathrm{LSD}^{\mathrm{a}}$ \\
\hline Alfalfa & $0.27^{b}$ & 1.11 & 1.39 & 1.34 & 1.25 & 1.59 & 1.27 & 1.20 & 1.05 & 1.21 & 1.21 & 1.50 & 0.83 & 1.23 & 1.37 & 0.32 \\
\hline Artichoke & 0.77 & 0.49 & 0.49 & 1.15 & 1.25 & 1.39 & 1.43 & 0.28 & 0.45 & 0.95 & 0.22 & 0.49 & 0.32 & 0.33 & 1.34 & 0.36 \\
\hline Bell pepper & 1.17 & 1.08 & 0.29 & 1.02 & 1.04 & 1.11 & 1.19 & 0.95 & 1.12 & 1.19 & 1.20 & 1.00 & 1.16 & 1.07 & 1.06 & 0.16 \\
\hline Cabbage & 1.59 & 1.30 & 1.64 & 1.45 & 0.85 & 1.43 & 1.38 & 1.40 & 1.56 & 1.49 & 1.70 & 1.61 & 1.61 & 1.53 & 1.41 & 0.45 \\
\hline Cauliflower & 1.11 & 1.05 & 1.18 & 0.77 & 0.59 & 1.31 & 1.04 & 1.18 & 1.23 & 1.33 & 1.22 & 1.28 & 1.19 & 0.93 & 1.42 & 0.28 \\
\hline Chili pepper & 0.75 & 0.92 & 0.09 & 0.9 & 0.81 & 0.92 & 1.00 & 0.64 & 0.81 & 0.75 & 0.50 & 0.95 & 0.71 & 0.88 & 1.04 & 0.15 \\
\hline Cotton & 0.06 & 0.13 & 0.22 & 0.34 & 0.29 & 0.37 & 0.11 & 0.33 & 0.13 & 0.13 & 0.22 & 0.18 & 0.09 & 0.11 & 0.45 & 0.12 \\
\hline Eggplant & 0.61 & 0.67 & 0.68 & 1.01 & 0.90 & 1.12 & 0.97 & 0.47 & 0.24 & 0.96 & 0.16 & 0.56 & 0.40 & 0.37 & 1.08 & 0.16 \\
\hline Lettuce & 2.17 & 2.09 & 1.94 & 2.22 & 2.04 & 2.11 & 2.14 & 1.80 & 1.08 & 2.16 & 2.01 & 1.58 & 2.01 & 1.70 & 2.18 & 0.44 \\
\hline Mint & 3.03 & 2.66 & 2.58 & 3.99 & 2.81 & 3.24 & 3.61 & 2.83 & 2.53 & 1.06 & 2.51 & 1.55 & 2.58 & 2.90 & 3.01 & 0.86 \\
\hline Potato & 5.36 & 4.66 & 6.55 & 6.48 & 5.09 & 6.82 & 6.35 & 5.21 & 2.80 & 6.97 & 3.30 & 3.85 & 3.49 & 3.44 & 7.72 & 1.76 \\
\hline Strawberry & 2.94 & 2.92 & 2.87 & 3.34 & 2.82 & 3.18 & 3.55 & 2.42 & 2.52 & 3.07 & 2.45 & 2.67 & 2.58 & 2.70 & 3.15 & 0.98 \\
\hline Tomato & 1.09 & 1.11 & 1.08 & 1.05 & 1.17 & 1.18 & 1.15 & 0.93 & 1.12 & 1.09 & 1.09 & 1.02 & 1.09 & 1.01 & 1.19 & 0.15 \\
\hline Watermelon & 0.05 & 0.07 & 0.07 & 0.34 & 0.3 & 0.38 & 0.39 & 0.04 & 0.07 & 0.43 & 0.04 & 0.08 & 0.06 & 0.06 & 0.63 & 0.12 \\
\hline
\end{tabular}

a Least significant difference test at $P \leq 0.05$.

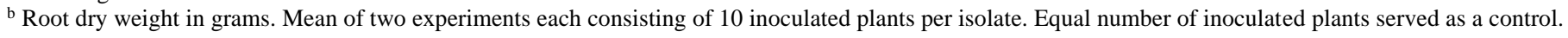

TABLE 6. Effect of Verticillium isolates from various crops on shoot dry weight of different hosts

Isolates

\begin{tabular}{|c|c|c|c|c|c|c|c|c|c|c|c|c|c|c|c|c|}
\hline Host & VaMs.102 & VdCs.80 & $\mathrm{VdCa} .59$ & VdBoc.74 & VdBob.70 & VdCa.31 & VdGh.101 & VdSm.113 & VdLs.7 & VdMp.89 & VdSt.91 & VdFca.21 & VdLe. 88 & VdCv.85 & Control & $\mathrm{LSD}^{\mathrm{a}}$ \\
\hline Alfalfa & $0.37^{b}$ & 2.02 & 2.31 & 2.21 & 2.40 & 2.54 & 2.15 & 2.25 & 1.94 & 2.19 & 2.08 & 2.79 & 1.76 & 2.21 & 2.59 & 0.72 \\
\hline Artichoke & 1.38 & 1.17 & 1.07 & 1.89 & 1.69 & 2.00 & 2.12 & 0.69 & 1.02 & 1.60 & 0.54 & 1.01 & 0.70 & 0.77 & 2.10 & 0.45 \\
\hline Bell Pepper & 1.35 & 1.48 & 0.04 & 1.42 & 1.30 & 1.49 & 1.54 & 1.29 & 1.44 & 1.65 & 1.55 & 1.39 & 1.49 & 1.49 & 1.44 & 0.2 \\
\hline Cabbage & 3.73 & 3.38 & 4.12 & 3.58 & 2.41 & 3.56 & 4.01 & 3.41 & 3.83 & 3.85 & 3.89 & 3.00 & 3.99 & 4.05 & 3.68 & 0.64 \\
\hline Cauliflower & 3.60 & 3.31 & 3.67 & 2.79 & 2.26 & 3.98 & 3.94 & 3.66 & 3.93 & 3.80 & 4.02 & 3.97 & 3.76 & 3.40 & 4.12 & 0.46 \\
\hline Chili Pepper & 1.27 & 1.34 & 0.15 & 1.33 & 1.23 & 1.47 & 1.6 & 0.99 & 1.32 & 1.29 & 0.91 & 1.42 & 1.19 & 1.33 & 1.51 & 0.21 \\
\hline Cotton & 0.26 & 0.59 & 0.95 & 1.35 & 1.12 & 1.26 & 0.49 & 1.25 & 0.64 & 0.59 & 1.07 & 0.71 & 0.34 & 0.44 & 1.57 & 0.32 \\
\hline Eggplant & 2.22 & 2.06 & 1.98 & 3.80 & 3.65 & 4.37 & 3.84 & 1.32 & 0.85 & 3.29 & 0.67 & 1.90 & 1.43 & 1.23 & 4.46 & 0.59 \\
\hline Lettuce & 5.08 & 4.99 & 4.80 & 4.67 & 4.49 & 4.97 & 5.01 & 4.10 & 2.84 & 5.08 & 4.69 & 4.22 & 4.23 & 4.39 & 4.95 & 0.83 \\
\hline Mint & 3.18 & 3.21 & 3.16 & 3.42 & 3.48 & 3.57 & 3.48 & 2.99 & 3.11 & 1.76 & 2.75 & 2.46 & 3.06 & 2.76 & 3.37 & 0.72 \\
\hline Potato & 0.99 & 1.05 & 1.10 & 1.10 & 1.05 & 1.09 & 1.15 & 7.40 & 0.77 & 1.01 & 0.69 & 0.80 & 0.68 & 0.61 & 1.27 & 2.59 \\
\hline Strawberry & 6.89 & 6.79 & 6.81 & 6.53 & 6.26 & 7.31 & 7.77 & 5.72 & 5.55 & 6.40 & 5.33 & 6.10 & 6.21 & 5.54 & 7.32 & 1.52 \\
\hline Tomato & 5.03 & 4.10 & 4.38 & 4.99 & 5.41 & 5.20 & 5.10 & 4.81 & 4.21 & 5.28 & 4.80 & 3.84 & 4.26 & 3.92 & 5.34 & 0.55 \\
\hline Watermelon & 0.54 & 0.90 & 0.48 & 1.98 & 2.00 & 2.28 & 2.71 & 4.70 & 0.60 & 2.85 & 0.44 & 0.75 & 0.64 & 0.58 & 3.62 & 0.64 \\
\hline
\end{tabular}

a Least significant difference test at $P \leq 0.05$.

b Shoot dry weight in grams. Mean of two experiments each consisting of 10 inoculated plants per isolate. Equal number of inoculated plants served as a control. 
most aggressive on artichoke, followed by eggplant, tomato, and watermelon isolates.

Bell pepper. Only bell pepper and eggplant isolates caused disease in $100 \%$ of the inoculated bell pepper plants (Table 2). The bell pepper isolate was highly pathogenic (Table 3 ) and caused wilting of bell pepper plants in addition to significant reductions in root and shoot biomass. In contrast, the eggplant isolate caused moderate root discoloration without any sign of wilting and significantly reduced only plant height (Tables 4, 5, and 6). Four isolates caused slight root discoloration in 60 to $80 \%$ of the plants, with no effect on the growth parameters. Thus, all isolates except from bell pepper and eggplant were nonpathogenic on bell pepper.

Cabbage. V. dahliae isolates from artichoke, cabbage, cauliflower, tomato, and watermelon and V. albo-atrum from alfalfa caused disease in $100 \%$ of the inoculated cabbage plants (Table 2). Plants inoculated with the cabbage and cauliflower isolates showed yellowing in the lower leaves, and the root and shoot vascular tissues were severely discolored. However, plants inoculated with artichoke,

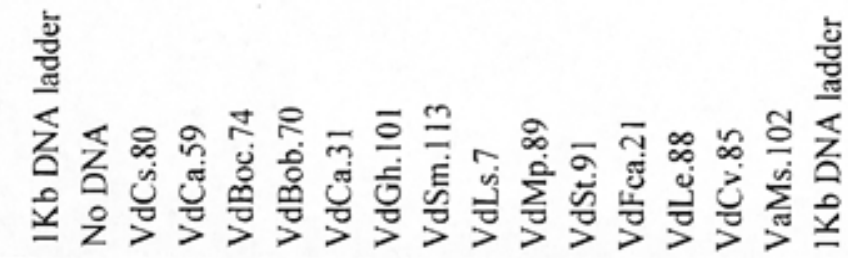

A
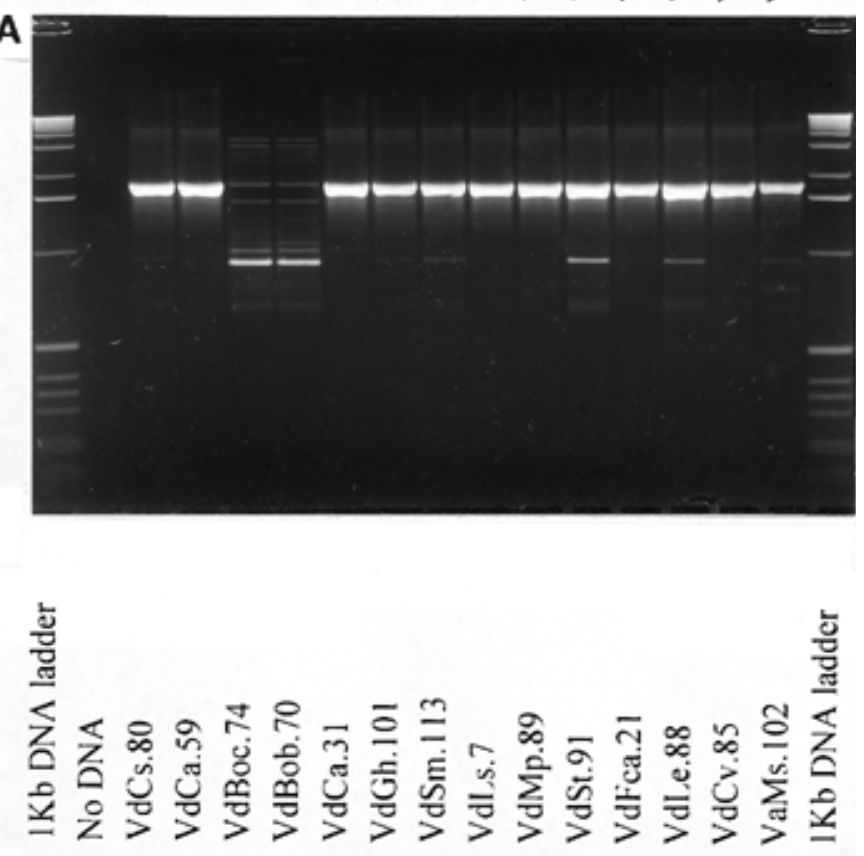

B

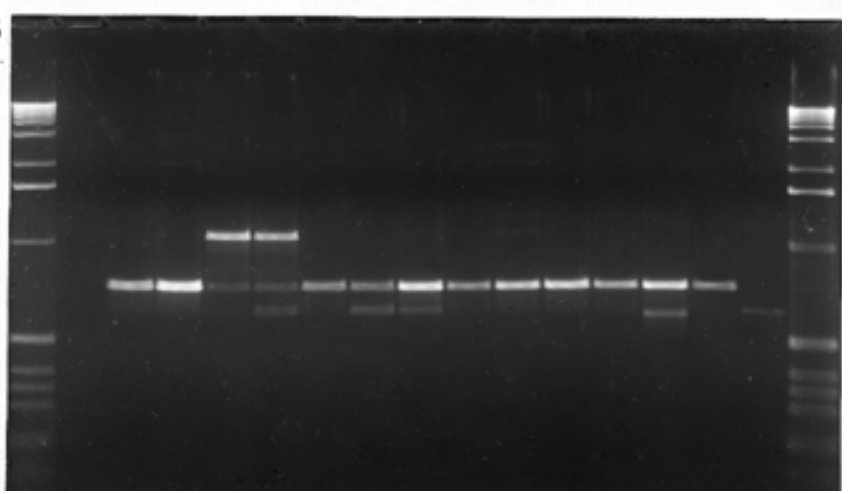

Fig. 1. Random amplified polymorphic DNA profiles of Verticillium DNA amplification with primers A, OPA-20 and B, OPB-01. watermelon, and tomato isolates did not show external symptoms, and only their roots were discolored. Isolates from lettuce, strawberry, mint, and potato were pathogenic on cabbage, but not aggressive. Bell pepper, cotton, and eggplant isolates were nonpathogenic. Plant height was not affected by $V$. dahliae infection (Table 4). Root and shoot dry weights of cabbage plants infected with only the cauliflower isolate were significantly reduced (Tables 5 and 6).

Cauliflower. Isolates from cabbage, cauliflower, potato, tomato, and watermelon caused disease in $100 \%$ of the plants and severely discolored roots in cauliflower (Table 2). There were significant reductions in plant height and root and shoot dry weights of cauliflower plants inoculated with the cabbage and cauliflower isolates (Tables 4, 5, and 6). Isolates of $V$. dahliae from bell pepper and mint and $V$. albo-atrum from alfalfa resulted in low disease severity $(\approx 2.0)$ (Table 3$)$. Isolates from artichoke, cotton, eggplant, lettuce, and strawberry were nonpathogenic.

Chili pepper. Thirteen isolates caused symptoms in more than $80 \%$ of the plants (Table 2). The $V$. dahliae isolate from bell pepper was highly pathogenic on chili pepper, followed by isolates from eggplant, lettuce, tomato, and watermelon and the V. albo-atrum isolate (Table 3). There was a severe reduction in plant growth and root and shoot dry weights of plants inoculated with the bell pepper isolate (Tables 4, 5, and 6). Isolates from artichoke, cauliflower, mint, potato, and strawberry caused a low disease severity of $\approx 2.0$, whereas isolates from cabbage and cotton were nonpathogenic.

Cotton. 'Acala SJ-2' plants were very susceptible to isolates of $V$. dahliae and V. albo-atrum (Table 2). Nine isolates caused severe wilting (Table 3), and four were defoliating strains. Moderate levels of root infection were observed in cotton plants inoculated with cauliflower, bell pepper, and eggplant isolates. The cabbage isolate was nonpathogenic. There were significant differences in plant growth parameters based on the severity of infection and wilting (Tables 4, 5, and 6).

Eggplant. Stunting and wilting of plants were observed in plants inoculated with isolates from eggplant, lettuce, potato, tomato, strawberry, and watermelon (Tables 2 and 3). Plant height was drastically reduced in those plants (Table 4). Similarly, significant differences in plant height and dry root and shoot mass were observed in plants inoculated with $V$. dahliae isolates from artichoke, and bell pepper and V. albo-atrum from alfalfa (Tables 4, 5, and 6), and only roots were discolored with no wilting symptoms (Table 3 ). The mint isolate was less aggressive, whereas isolates from cabbage, cauliflower, and cotton were nonpathogenic.

Lettuce. The lettuce isolate was highly pathogenic, causing severe root vascular discoloration and yellowing of lower leaves in lettuce, followed by the watermelon isolate with only root discoloration (Table 3). These two isolates caused significant reductions in root and shoot growth (Tables 5 and 6). Isolates from artichoke, eggplant, potato, strawberry, and tomato caused vascular discoloration in 60 to $100 \%$ of the lettuce plants, with mild to moderate root damage (Table 2), but did not affect plant growth (Table 4). V. dahliae isolates from bell pepper, cabbage, cauliflower, cotton, and mint and V. albo-atrum from alfalfa were nonpathogenic.

Mint. Isolates from artichoke, lettuce, mint, potato, strawberry, and watermelon caused disease on all the mint plants inoculated, and only the mint isolate was aggressive enough to cause wilting (Tables 2 and 3). This isolate caused significant reductions in plant height and root and shoot dry weights (Tables 4, 5, and 6). The tomato isolate incited only moderate root discoloration. Isolates of $V$. dahliae from bell pepper, cabbage, cauliflower, cotton, and eggplant and $V$. albo-atrum from alfalfa were nonpathogenic to mint.

Potato. V. dahliae isolates from artichoke, eggplant, lettuce, potato, strawberry, tomato, and watermelon caused severe vascular discoloration and wilting in the potato plants (Tables 2 and 3), which resulted in significant differences in tuber and plant growth (Tables 4, 5, and 6). Also, V. albo-atrum from alfalfa caused vascular discoloration, but potato plants were not wilted 6 weeks after 
inoculation. The bell pepper, cabbage, and cauliflower isolates were less aggressive. The cotton and mint isolates were nonpathogenic.

Strawberry. Twelve isolates caused severe crown discoloration, and four of them wilted the strawberry plants within 6 weeks after inoculation (Tables 2 and 3). However, in many host $\times$ isolate combinations, plant height and root and shoot dry weights were not significantly different from the control (Tables 4, 5, and 6). The cotton isolate was nonpathogenic.

Tomato. None of the isolates caused wilting in the tomato plants. Isolates from artichoke, tomato, strawberry, and watermelon discolored roots severely in all plants (Tables 2 and 3) and reduced the shoot dry weight significantly (Table 6). There were a few other significant differences in plant height and root and shoot dry weights among different treatments (Tables 4, 5, and 6). V. dahliae isolates from bell pepper, and lettuce and V. albo-atrum from alfalfa caused moderate root discoloration without any significant reduction in plant height and root dry weight. But there were significant differences in shoot dry weight of plants infected with the bell pepper and lettuce isolates. Isolates from cabbage, cauliflower, cotton, eggplant, mint, and potato were nonpathogenic.

Watermelon. Eleven isolates were pathogenic and highly aggressive on the watermelon plants (Table 2), and nine of them wilted the plants within 1 week after inoculation (Table 3). The plants did not establish themselves in the pots after inoculation. The cabbage and cauliflower isolates did not wilt the plants. However, plant height and root and shoot dry weights were reduced approximately $50 \%$ by these two isolates (Tables 4,5 , and 6 ). The cotton and mint isolates were considered nonpathogenic, since there was only slight root discoloration.

Vegetative compatibility of $\boldsymbol{V}$. dahliae isolates. nit Mutants were obtained from all but the cabbage and cauliflower isolates. In all, 107 nit mutants were paired with NitMs of standard VCGs. One hundred and three nit mutants were compatible with one of the standard VCGs. Only four nit mutants, three from the mint isolate and one from the tomato isolate, were incompatible with the standard VCGs. There were other nit mutants from each of these two isolates that formed heterokaryons with a known VCG. Only the cotton isolate belonged to VCG 1 (Table 1). The isolates from artichoke, chili pepper, lettuce, mint, strawberry, and watermelon belonged to VCG 2 . Four isolates from bell pepper, eggplant, potato, and tomato were associated with VCG 4. nit Mutants from the potato isolate differed from other nit mutants in their compatibility with tester strains. Out of eight nit mutants from the potato isolate, three belonged to VCG 4 and five to VCGs 3 and 4. However, the intensity of heterokaryon formation and dense prototrophic mycelial growth of these five nit mutants from the potato isolate was more pronounced with tester VCG 4 than with VCG 3. nit Mutants from V. albo-atrum were not compatible with any of the tester NitM strains of $V$. dahliae.

RAPD analysis. Of the 40 random primers tested, 18 amplified DNA fragments from thirteen $V$. dahliae isolates and one V. alboatrum isolate. Amplification was identical in two separate experiments. All amplified fragments were scored and given numbers based on their sizes. The fragments varied in size from 290 to 3,300 base pairs. Typical amplification results from two primers for 14 isolates are shown in Figure 1. A total of 160 fragments was amplified from all isolates, and these were used for analysis. Three major groups were evident in isolates used in this study (Fig. 2). There were major differences in neutral markers among these three groups. Group 1 consisted of $V$. dahliae isolates from crops other than cabbage and cauliflower, group 2 consisted of isolates from cabbage and cauliflower, and group 3 consisted of a $V$. albo-atrum isolate. Variation in RAPD profile was observed with certain primers in group 1 isolates, and isolates in this group were further clustered into four subgroups. Subgroup 1A contained isolates from artichoke, lettuce, strawberry, tomato, and watermelon; subgroup 1B contained isolates from chili pepper, eggplant, mint, and potato; subgroup 1C contained an isolate from bell pepper; and subgroup 1D contained an isolate from cotton. However, RAPD banding patterns in group 1 isolates were not related to either pathogenicity or vegetative compatibility.

\section{DISCUSSION}

In this study, pathogenicity tests of 14 Verticillium isolates on all 14 hosts provided credible information on the host range of each isolate. The data indicated that there are host specialization and differential pathogenicity in isolates from certain hosts of $V$. dahliae. Bell pepper, cabbage, cauliflower, cotton, eggplant, and mint isolates exhibited host range specificity, whereas isolates from artichoke, lettuce, potato, strawberry, tomato, and watermelon did not. There are earlier reports on host adaptability or specificity in $V$. dahliae and V. albo-atrum $(15,17,33,39,41,46)$. On peppermint plants, Verticillium isolates from tomato and radish were infective, but the isolates from potato, eggplant, nightshade, okra, and melon were not (15). Similarly, cotton isolates did not produce wilt symptoms in cowpea, muskmelon, and watermelon, but were differentially pathogenic on cotton, tomato, safflower, and snapdragon (41). Host specificity of $V$. dahliae was recognized on tomato, eggplant, bell pepper, and cruciferous plants (17). All tested Brazilian cocoa isolates caused severe symptoms on eggplant, but few or no symptoms on pepper (39). V. albo-atrum was differentiated into two groups based on RFLPs, and both groups were pathogenic to their respective hosts only (33). Our results support and contradict some of these earlier reports. Host range specificity is a characteristic of an isolate from a particular host. In nature, a strong selection pressure is exerted on the field isolates, and only those isolates that are aggressive on a particular host can cause severe vascular discoloration and wilting. For example, the bell pepper isolate, VdCa.59, caused severe wilting in bell pepper and a moderate level of vascular discoloration in strawberry roots, whereas the strawberry isolate, VdFca.21, did not cause disease in bell pepper, but wilted strawberry plants. In a cross-infectivity study, it is possible to recover 'bell pepper isolate' from discolored strawberry roots inoculated with the bell pepper isolate. But, such an isolate is not considered a 'strawberry' isolate, because it cannot cause severe vascular discoloration and wilting in strawberry (similar to the strawberry isolate itself). In extended analyses of four additional $V$. dahliae isolates from each host on all hosts, we observed that isolates from individual hosts have similar host ranges, although their aggressive-

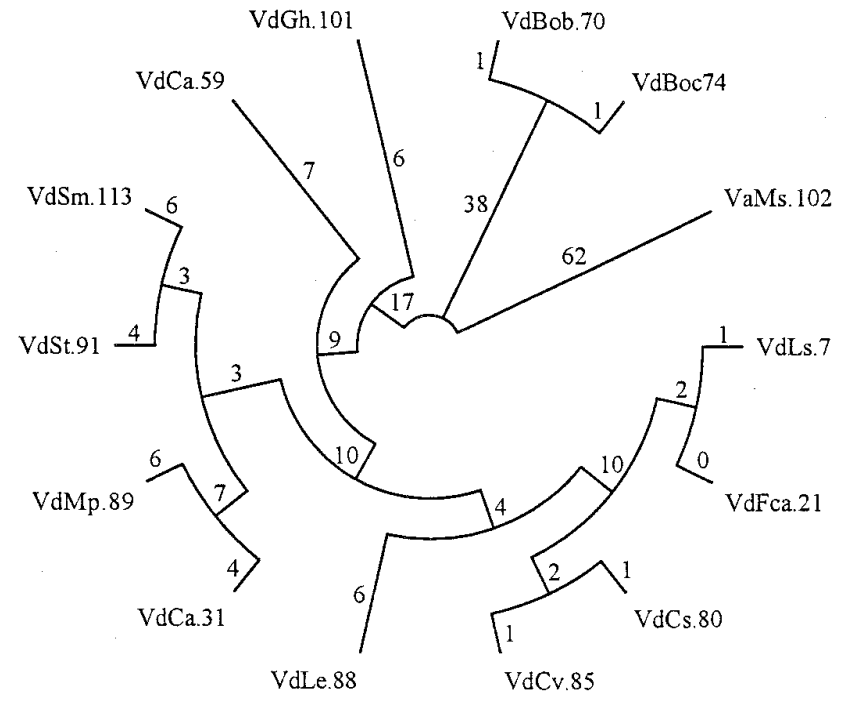

Fig. 2. Phylogenetic relationships among thirteen Verticillium dahliae and one $V$. albo-atrum isolate based on the analysis of random amplified polymorphic DNA markers. Heuristic search analysis was conducted using PAUP version $4.0 \mathrm{~b} 2$. Branch lengths are indicated in a circletree. 
ness on specific hosts may differ (R. G. Bhat and K. V. Subbarao, unpublished data).

With the exception of the chili pepper isolate, all isolates were pathogenic and very aggressive on the hosts from which they were originally isolated. The chili pepper isolate was pathogenic in a previous study (43), but has apparently become attenuated since that time. All other isolates exhibited variation in their pathogenicity on various hosts. The reaction ranged from highly aggressive to nonpathogenic, depending on the isolate $\times$ host combination. Similar patterns of infections by Verticillium have been reported in several other host plants $(6,9,18)$.

Results of seedling tests in the greenhouse are predictive of host range in the field. Thus, suitable crop rotations can be determined to manage Verticillium wilt based on our data. For example, bell pepper could be rotated with lettuce, since the isolates from these two hosts are not cross-infective. Alfalfa could also be rotated with bell pepper to reduce the buildup of Verticillium inoculum. Broccoli is immune to $V$. dahliae isolates from various hosts and resistant to cabbage and cauliflower isolates $(43,44 ;$ R. G. Bhat and $\mathrm{K}$. V. Subbarao, unpublished data). A cropping sequence of lettucebell pepper-broccoli might drastically reduce Verticillium infection. V. dahliae microsclerotia can survive in soil for many years (12) and can cause Verticillium wilt. But, rotations with broccoli result in significant reductions in the soilborne microsclerotia within a few years (44). These hypothetical cropping sequences need to be tested under field conditions to determine their efficacy and practicality.

Disease scoring for symptoms such as vascular discoloration and wilting is perhaps the most appropriate method of evaluating pathogenicity and aggressiveness of Verticillium isolates. Measurements on growth parameters such as plant height and root and shoot dry weights do not reflect the true potential of an isolate to cause disease in some hosts such as cauliflower, lettuce, and strawberry. Therefore, interpreting results solely on the basis of effects on growth parameters may not be accurate. Disease scoring in combination with growth parameters, as done in this study, is more meaningful for the evaluation of pathogenicity. It has been reported that $V$. dahliae could be recovered from asymptomatic roots (6). In our study, $V$. dahliae pure cultures were obtained only from the symptomatic root tissues (data not shown).

Of the $13 \mathrm{~V}$. dahliae isolates tested for vegetative compatibility, 10 isolates were from California-two from cruciferous and eight from noncruciferous crops. The cabbage and cauliflower isolates failed to produce nit mutants, and thus, they could not be grouped into any VCG. In a previous study, Subbarao et al. (43) also reported their inability to obtain nit mutants from crucifer isolates. They and others have speculated that nit mutants could not be obtained, perhaps because crucifer isolates are diploid $(21,22,43)$. All eight noncrucifer isolates readily produced nit mutants, indicating that they are genetically different from crucifer isolates. In California, the isolates from artichoke, chili pepper, lettuce, strawberry, and watermelon belonged to VCG 2; isolates from bell pepper and tomato, to VCG 4; and an isolate from cotton, to VCG 1. Therefore, the majority of isolates originating from various hosts in California belonged to VCG 2. This is in agreement with a report by Strausbaugh et al. (42), who observed many isolates from California potatoes belonging to VCG 2. However, vegetative compatibility was not associated with host pathogenicity.

Eighteen random primers amplified different-sized DNA fragments from genomes of Verticillium species. Amplified DNA fragments revealed that there are three major groups of Verticillium isolates. RAPD marker profiles of Verticillium isolates from cruciferous and noncruciferous crops and the V. albo-atrum isolate from alfalfa were totally different from each other. Furthermore, RAPD patterns were not associated with VCGs or pathogenicity in $V$. dahliae, indicating that RAPD fragments are neutral and independent of the phenotypic traits. This is consistent with previous reports $(2,22,28,38)$ on $V$. dahliae and $V$. albo-atrum isolates. Screen- ing greater numbers of random primers may reveal DNA markers linked with pathogenicity and morphological traits in Verticillium species.

Recently, Karapapa et al. (21) designated Verticillium species infecting oilseed rape and other crucifers as $V$. longisporum because of distinct RAPD band profiles, long, 'near-diploid' conidia, elongated microsclerotia, and host specificity. They also suggested that $V$. longisporum might have evolved by parasexual hybridization between $V$. dahliae and V. albo-atrum. However, in our study, many of the DNA markers amplified from crucifer isolates were not present in either $V$. dahliae or $V$. albo-atrum. Moreover, as evident in the vegetative compatibility study, there is a barrier between $V$. albo-atrum and $V$. dahliae to form heterokaryons. This might prevent genetic exchanges between these two species to form a new species. Karapapa et al. (21) reported that crucifer isolates might be the result of hybridization between $V$. dahliae and $V$. albo-atrum; while this is an interesting possibility, our data do not support such a conclusion.

Each isolate from bell pepper, cabbage, cauliflower, and cotton in California has limited host ranges, and they are in distinct genetic groups based on vegetative compatibility and RAPD profiles. Therefore, they are unlikely to interact and give rise to isolates with new specificity. However, other $V$. dahliae isolates in California with broad host ranges, except the one from tomato, belong to the same VCG 2 and share similar RAPD banding patterns. These isolates are either clones of a single strain or they evolved through asexual recombination. There is a possibility that, in nature, isolates belonging to the same VCG exchange genetic material through heterokaryosis. Under field conditions, isolates with different host range specificity can infect a particular host. When isolates belonging to the same VCG coinfect a host, there are ample opportunities for parasexual reproduction to occur and to produce recombinants possessing new host specificity. The succeeding crops might select these recombinants. We are currently examining this phenomenon by selectively pairing the isolates with known host range specificity and RAPD markers to recover recombinants.

\section{ACKNOWLEDGMENTS}

This research was supported, in part, by funding from the California Lettuce Board and California Pepper Commission. We thank C. Lambert and M. Orozco for their assistance in the inoculation studies in the greenhouse, and D. Fravel, T. Gordon, K. Johnson, S. Koike, B. Pennypacker, M. Powelson, and R. Smith for providing various Verticillium isolates. We also thank T. Gordon and M. Powelson for their critical presubmission review of the manuscript and suggestions.

\section{LITERATURE CITED}

1. Bao, J. R., Katan, J., Shabi, E., and Katan, T. 1998. Vegetative-compatibility groups in Verticillium dahliae from Israel. Eur. J. Plant Pathol. 104:263-269.

2. Barasubiye, T., Parent, J. G., Hamelin, R. C., Laberge, S., Richard, C., and Dostaler, D. 1995. Discrimination between alfalfa and potato isolates of Verticillium albo-atrum using RAPD markers. Mycol. Res. 99: 1507-1512.

3. Bhat, R. G., and Subbarao, K. V. 1998. Genetic characterization of Verticillium dahliae isolates using RAPD-PCR and vegetative compatibility. (Abstr.) Phytopathology 88(suppl.):S8.

4. Bhat, R. G., and Subbarao, K. V. 1998. Host specificity in Verticillium dahliae. (Abstr.) Phytopathology 88(suppl.):S8.

5. Carder, J. H., and Barbara, D. J. 1991. Molecular variation and restriction fragment length polymorphisms (RFLPs) within and between six species of Verticillium. Mycol. Res. 95:935-942.

6. Chang, R. J., and Eastburn, D. M. 1994. Host range of Verticillium dahliae from horseradish and pathogenicity of strains. Plant Dis. 78:503-506.

7. Chen, W. 1994. Vegetative compatibility groups of Verticillium dahliae from ornamental woody plants. Phytopathology 84:214-219.

8. Christie, T. 1966. The pathogenicities of seven isolates of Verticillium to tobacco. N.Z. J. Agric. Res. 9:149-151

9. Ciccarese, F., Frisullo, S., and Cirulli, M. 1987. Severe outbreaks of Verticillium wilt on Cichorium intybus and Brassica rapa and patho- 
genic variations among isolates of Verticillium dahliae. Plant Dis. 71: 1144-1145.

10. Correll, J. C., Gordon, T. R., and McCain, A. H. 1988. Vegetative compatibility and pathogenicity of Verticillium albo-atrum. Phytopathology 78:1017-1021.

11. Daayf, F., Nicole, M., and Geiger, J. P. 1990. Differentiation of Verticillium dahliae populations on the basis of vegetative compatibility and pathogenicity on cotton. Eur. J. Plant Pathol. 101:69-79.

12. Davis, J. R., Pavek, J. J., Corsini, D. L., Sorensen, L. H., Schneider, A. T., Everson, D. O., Westermann, D. T., and Huisman, O. C. 1994. Influence of continuous cropping of several potato clones on the epidemiology of Verticillium wilt of potato. Phytopathology 84:207-214.

13. Eastburn, D. M., and Chang, R. J. 1994. Verticillium dahliae: A causal agent of root discoloration of horseradish in Illinois. Plant Dis. 78:496498.

14. Elena, K., and Paplomatas, E. J. 1998. Vegetative compatibility groups within Verticillium dahliae isolates from different hosts in Greece. Plant Pathol. 47:635-640.

15. Green, R. J. 1951. Studies on the host range of the Verticillium that causes wilt of Mentha piperita L. Science 113:207-208

16. Hastie, A. C., and Heale, J. B. 1984. Genetics of Verticillium. Phytopathol. Mediterr. 23:130-162.

17. Horiuchi, S., Hagiwara, H., and Takeuchi, S. 1990. Host specificity of isolates of Verticillium dahliae towards cruciferous and solanaceous plants. Pages 285-298 in: Biological Control of Soil-Borne Plant Pathogens. D. Hornby, ed. CAB International, Wallingford, England.

18. Horner, C. E. 1954. Pathogenicity of Verticillium isolates to peppermint. Phytopathology 44:239-242.

19. Isaac, I., and Keyworth, W. G. 1958. Verticillium wilt of the hop (Humulus lupulus). III. A study of the pathogenicity of isolates from fluctuating and from progressive outbreaks. Ann. Appl. Biol. 35:243-249.

20. Joaquim, T. R., and Rowe, C. R. 1990. Reassessment of vegetative compatibility relationships among strains of Verticillium dahliae using nitrate-nonutilizing mutants. Phytopathology 80:1160-1166.

21. Karapapa, V. K., Bainbridge, B. W., and Heale, J. B. 1997. Morphological and molecular characterization of Verticillium longisporum comb. nov., pathogenic to oilseed rape. Mycol. Res. 101:1281-1294.

22. Koike, M., Fujita, M., Nagao, H., and Ohshima, S. 1996. Random amplified polymorphic DNA analysis of Japanese isolates of Verticillium dahliae and V. albo-atrum. Plant Dis. 80:1224-1227.

23. Koike, S. T., Subbarao, K. V., Davis, R. M., Gordon, T. R., and Hubbard, J. C. 1994. Verticillium wilt of cauliflower in California. Plant Dis. 78: 1116-1121.

24. Korolev, N., and Katan, T. 1997. Improved medium for selecting nitratenonutilizing (nit) mutants of Verticillium dahliae. Phytopathology 87: 1067-1070.

25. Krikun, J., and Bernier, C. C. 1987. Infection of several crop species by two isolates of Verticillium dahliae. Can. J. Plant Pathol. 9:241-245.

26. Lee, S. B., and Taylor, J. W. 1990. Isolation of DNA from fungal mycelia and single spores. Pages 282-287 in: PCR Protocols: A Guide to Methods and Applications. M. A. Innes, D. H. Gelfand, J. J. Sninsky, and T. J. White, eds. Academic Press, San Diego, CA.

27. McCain, A. H., Raabe, R. D., and Wilhelm, S. 1981. Plants Resistant or Susceptible to Verticillium Wilt. Cooperative Extension, U.S. Department of Agriculture, University of California, Berkeley.

28. Messner, R., Schweigkofler, W., Ibl, M., Berg, G., and Prillinger, H. 1996. Molecular characterization of the plant pathogen Verticillium dahliae Kleb. using RAPD-PCR and sequencing of the 18SrRNA-gene. J. Phytopathol. 144:347-354.

29. Morton, A., Carder, J. H., and Barbara, D. J. 1995. Sequence of the internal transcribed spacers of the ribosomal RNA genes and relationships between isolates of Verticillium albo-atrum and V. dahliae. Plant Pathol. 44:183-190.

30. Nagao, H., Shiraishi, T., Oshima, S., Koike, M., and Iijima, T. 1997. Assessment of vegetative compatibility of race-2 tomato wilt isolates of Verticillium dahliae in Japan. Mycoscience 38:379-385.

31. Nazar, R. N., Hu, X., Schmidt, J., Culham, D., and Robb, J. 1991. Potential use of PCR-amplified ribosomal intergenic sequences in the detection and differentiation of Verticillium wilt pathogens. Physiol. Mol. Plant Pathol. 39:1-11.

32. O'Garro, L. W., and Clarkson, J. M. 1988. Heterokaryon incompatibility and heterozygous diploid production in tomato wilt isolates of Verticillium dahliae. J. Gen. Microbiol. 134:2977-2984.

33. Okoli, C. A. N., Carder, J. H., and Barbara, D. J. 1994. Restriction fragment length polymorphisms (RFLPs) and the relationships of some hostadapted isolates of Verticillium dahliae. Plant Pathol. 43:33-40.

34. Pegg, G. F. 1984. The impact of Verticillium diseases in agriculture. Phytopathol. Mediterr. 23:176-192.

35. Puhalla, J. E. 1979. Classification of isolates of Verticillium dahliae based on heterokaryon incompatibility. Phytopathology 69:1186-1189.

36. Puhalla, J. E. 1985. Classification of strains of Fusarium oxysporum on the basis of vegetative compatibility. Can. J. Bot. 63:179-183.

37. Puhalla, J. E., and Hummel, M. 1983. Vegetative compatibility groups within Verticillium dahliae. Phytopathology 73:1305-1308.

38. Ramsay, J. R., Multani, D. S., and Lyon, B. R. 1996. RAPD-PCR identification of Verticillium dahliae isolates with differential pathogenicity on cotton. Aust. J. Agric. Res. 47:682-693.

39. Resende, M. L. V., Flood, J., and Cooper, R. M. 1994. Host specialization of Verticillium dahliae, with emphasis on isolates from cocoa (Theobroma cacao). Plant Pathol. 43:104-111.

40. Rowe, R. C. 1995. Recent progress in understanding relationships between Verticillium species and subspecific groups. Phytoparasitica 23: 31-38.

41. Schnathorst, W. C., and Mathre, D. E. 1966. Host range and differentiation of a severe form of Verticillium albo-atrum in cotton. Phytopathology 56:1155-1161.

42. Strausbaugh, C. A., Schroth, M. N., Weinhold, A. R., and Hancock, J. G. 1992. Assessment of vegetative compatibility of Verticillium dahliae tester strains and isolates from California potatoes. Phytopathology 82: 61-68.

43. Subbarao, K. V., Chassot, A., Gordon, T. R., Hubbard, J. C., Bonello, P., Mullin, R., Okamoto, D., Davis, R. M., and Koike, S. T. 1995. Genetic relationships and cross pathogenicities of Verticillium dahliae isolates from cauliflower and other crops. Phytopathology 85:1105-1112.

44. Subbarao, K. V., and Hubbard, J. C. 1996. Interactive effects of broccoli residue and temperature on Verticillium dahliae microsclerotia in soil and on wilt in cauliflower. Phytopathology 86:1303-1310.

45. Subbarao, K. V., Hubbard, J. C., Greathead, A. S., and Spencer, G. A 1997. Verticillium wilt. Pages 26-27 in: Compendium of Lettuce Diseases. R. M. Davis, K. V. Subbarao, R. N. Raid, and E. A. Kurtz, eds. The American Phytopathological Society, St. Paul, MN.

46. Taylor, J. B. 1969. Host specificity of Verticillium dahliae to tobacco. N.Z. J. Sci. 12:709-712.

47. Tjamos, E. C. 1981. Virulence of Verticillium dahliae and V. albo-atrum isolates in tomato seedlings in relation to their host of origin and the applied cropping system. Phytopathology 71:98-100.

48. Williams, J. G. K., Kubelik, A. R., Livak, K. J., Rafalsky, J. A., and Tingey, S. V. 1990. DNA polymorphisms amplified by arbitrary primers are useful as genetic markers. Nucleic Acids Res. 18:6531-6535.

49. Woolliams, G. E. 1966. Host range and symptomatology of Verticillium dahliae in economic, weed, and native plants in interior British Columbia. Can. J. Plant Sci. 46:661-669. 